\title{
Políticas públicas de inclusión en la educación superior Los casos de Argentina y Brasil
}

Adriana Chiroleu *

Resumen: Las políticasinclusivasen la educación superior seorientan alograr quelasinstituciones contengan una diversidad racial, cultural y sexual semejante a la que existe en el seno de la sociedad, en procura deremediar discriminacioneshistóricas quehan conducido al a situación de desigualdad por la que atraviesan esos grupos. En este sentido, la implementación en al gunos países de Políticas deAcción A firmativa en el ámbito dela educación superior procura una mayor integración social en sociedades caracterizadas por fragmentaciones de diferente natural eza. En estetrabajo nos proponemos abordar desdeuna perspectiva comparativa los alcances de las políticas públicas deinclusión en la universidad quese desarrollan en Argentina y B rasil, enmarcándolas en los rasgos diferenciales de sus estructuras social es y sussistemas de Educación superior.

Palabras-clave: universidad; políticas deacción afirmativa; Argentina-Brasil; políticas públicas.

Public policies for inclusion in higher education The Argentinian and Brazilian cases

Abstract: Inclusive policies in higher education are planned to achieve racial, cultural and sexual diversity in institutions, similarly to social diversity itself. Such policiesare intended to repair historical discrimination that has contributed to the unequal situation those groups have been facing. For such, the establishment of Affirmative Action Policies in the higher education field in somecountriesisintended to achievegreater social integration in societies that are usually characterized by fragmentation of different kinds. T he purpose of this paper is to address, from a comparative perspective, the advances of public policies for university inclusion in Argentina and Brazil, considering the differences between their social structures and higher education systems.

Key words: university; affirmativeaction policies; Argentina-Brazil; public policies.

El sostenimiento de los principios igualitaristas de la Revolución Francesa organizó a la sociedad moderna en torno a una lógica inclusiva en la cual la

\footnotetext{
Doctora en Ciencias Sociales (Facultad Latinoamericana de Ciencias Sociales - Flacso Argentina / Universidad de Brasilia); Docente de la Facultad de Ciencia Política y RRII - Universidad Nacional de Rosario e Investigadora del Consejo Nacional de Investigaciones Científicas y Técnicas (Conicet), Argentina. achiroleu@arnet.com.ar
} 
movilidad social ascendente constituía un instrumento privilegiado de cohesión y garantía de una cierta fluidez social. D esde los años '90 sin embargo, a contramano de estos valores ya fuertemente arraigados en la sociedad occidental, la exclusión social comienza a ser reconocida como el mayor problema a enfrentar en las próximas décadas (Rosanvallon, 1995). En este caso, el debate en torno a sus alcances y consecuencias la relacionan directamente con la expansión del desempleo de larga duración y la nueva pobreza, consecuencias de la reestructuración productiva, la recomposición de las relaciones de trabajo y la acentuación de la competencia internacional, rasgos que van asociados al intenso proceso de globalización que tiene lugar a partir de las últimas décadas del siglo pasado.

D e esta manera, se acentúan las inequidades y se pone en marcha una dinámica profundamente desigualitaria que supone una cristalización de las diferencias en las condiciones iniciales de los individuos: esto es, quienes se benefician son aquellos que provienen de hogares que tienen una importante acumulación de capital y/o de saber, mientras que los que carecen de estos activos, tienden a quedar relegados (Fitoussi; Rosanvallon, 1997, p. 141).

Esta flagrante contradicción entre una lógica de inclusión, producto virtuoso de la modernidad, y una realidad de exclusión, fruto de la nueva estrategia desarticulada de acumulación vigente, merece interpretarse como una solución deliberada y hasta inevitable ante la aplicación de políticas neoliberales y el enorme desarrollo tecnológico que se genera en las últimas décadas del siglo XX.

En el caso de la educación superior, y especialmente de la universitaria, esta relación inclusión - exclusión, adquiere connotaciones y alcances particulares. Como punto de partida, corresponde encuadrarla en instituciones que, desde sus propios orígenes privilegiaron el mérito y la excelencia, principios que por entonces constituían una oportunidad de mitigar la incidencia de factores adscriptivos en una sociedad fuertemente jerarquizada como la medieval, dotada de una estructura social estática y lugares sociales cristalizados.

El debate actual en cambio, introduce nuevos elementos en la medida en que se apunta a incluir dentro de la universidad una diversidad racial, cultural y sexual semejante a la que existe en el seno de la sociedad, en procura de remediar discriminaciones históricas que han conducido a la situación de desigualdad por la que atraviesan esos grupos. En este sentido, la implementación en algunos países de Políticas de Acción Afirmativa en el ámbito de la educación superior intenta lograr una mayor integración social en sociedades caracterizadas por fragmentaciones de diferente naturaleza.

Por eso, aunque parezca paradójico que estas preocupaciones se presenten en momentos en que se extiende la exclusión de ciertos individuos y grupos; las mismas pueden interpretarse precisamente como propuestas para contener 
parcialmente los procesos de fragmentación que socavan la cohesión social. N o suponen sin embargo, cambios estructurales sino un acercamiento a la institución de ciertos grupos, para los que se generan únicamente, condiciones mínimas para su acceso.

¿C uáles son los alcances del concepto de inclusión en la universidad? ¿Cómo se articulan las Políticas de Acción Afirmativa que se diseñan desde los gobiernos en instituciones básicamente meritocráticas? ¿Puede constituir este tipo de políticas una forma eficaz para lograr una mayor integración social en países marcados por la desigualdad como los de América Latina?

En este trabajo nos proponemos abordar desde una perspectiva comparativa los alcances de las políticas públicas de inclusión en la universidad que se desarrollan en Argentina y Brasil, enmarcándolas en los rasgos diferenciales de sus estructuras sociales y sus sistemas de educación superior. Para hacerlo, partimos de una breve presentación de algunos aspectos teórico-conceptuales de la temática que autorice una complejización de las principales aristas problemáticas de la misma.

Las singularidades de la inclusión en la educación superior: notas sobre equidad, mérito y meritocracia

El desarrollo de políticas inclusivas en la educación superior supone el desafío de superar la doble contradicción que les da origen: por una parte, su implantación en el contexto de sociedades en las que paradójicamente - se exacerba la exclusión y la fragmentación social, y por la otra, su localización en un ámbito tradicionalmente refractario a las tendencias igualitaristas, como es el del tercer nivel educativo, especialmente en el subsector universitario.

En este sentido, la primacía de valores como la excelencia y el mérito, componentes indisociables de la educación superior, se asocia contemporáneamente con lógicas excluyentes. Esto, sin embargo, no siempre fue así, pues en el contexto sociopolítico medieval la imposición de estos criterios en el seno de las universidades permitía desplazar y aun subordinar a factores adscriptivos como la clase social de pertenencia, la raza o el color: la premisa general suponía que la inclusión en el nivel superior de individuos o grupos debía responder estrictamente a sus propios logros y corresponder a cualquier persona que a partir de sus cualidades, esfuerzo, y dedicación, alcanzara ciertas metas u objetivos.

El concepto de mérito sin embargo no es unívoco y sus alcances y consecuencias son leídos incluso de manera opuesta por los diversos paradigmas. En efecto, para al gunos supone que el acceso y el progreso dentro de la institución están única y estrechamente vinculados a las realizaciones personales. En este caso se focaliza en el individuo y se considera que las personas son premiadas 
por sus acciones y sus logros, los cuales se ligan al esfuerzo, la perseverancia y el trabajo permanente, a la par que sostienen que - independientemente de su origen y situación inicial - cualquier persona dispuesta a someterse a ese esfuerzo alcanzaría las mismas metas.

Precisamente, el hecho de que los logros académicos individuales no siempre puedan explicarse por los orígenes sociales ha llevado a algunos autores a considerar al mérito como una herramienta de igualación y un mecanismo de fluidez social capaz de quebrar las rigideces de la estratificación social. Para otros, en cambio, este planteo encierra una falsa igualdad de oportunidades entre los actores intervinientes, pues ésta se encuentra fuertemente mediada por factores adscriptivos por no tratarse de un concepto universal y, en consecuencia, merecer diferentes lecturas desde la perspectiva social.

La introducción de la noción de inclusión cambia sin embargo el eje de discusión al tomar como punto de partida el reconocimiento de que la sociedad no es homogénea y la diversidad constituye un componente fundamental que merece ser revalorizado. Esto supone un cambio sustancial del foco de análisis en la medida en que, tradicionalmente, se consideró a la diversidad una desventaja y un obstáculo a remover para construir sociedades homogéneas, requisito indispensable de un estado-nación en sentido clásico. En el ámbito educativo ${ }^{1}$, supone el derecho al aprendizaje por parte de todos, independientemente de sus características individuales, con el fin de proporcionar atención al conjunto de demandantes según sus propias necesidades, lo que implica velar y generar condiciones adecuadas para la obtención de resultados favorables.

La aplicación de este concepto en el ámbito de la educación superior adquiere una mayor complejidad en la medida en que requiere ser articulado con las nociones de mérito y excelencia fuertemente presentes en el nivel. En este sentido, Renaut (2008) hace referencia al dilema que se plantea en las instituciones: si se elimina el elitismo, se corre el riesgo de perder el ideal de excelencia, pero si se prescinde del componente democrático, la excelencia queda reservada a unos pocos. D e esta manera, resulta fundamental que la universidad busque alternativas que permitan superar esta tensión.

Por otra parte, la igualdad (formal) de oportunidades para acceder a las instituciones poco nos dice sobre la posibilidad concreta de obtener resultados positivos en el tránsito por las mismas. Para Bourdieu y Passeron (2006) la afinidad entre los hábitos culturales de una clase y las exigencias del sistema de

Los alcances del concepto de inclusión en la educación comienza a ser debatida a partir de la Conferencia de la UNESCO de Tailandia (1990). Unos años más tarde, en la Conferencia de Salamanca (1994) esta idea se consolida y se promueve el objetivo de la Educación para Todos. 
enseñanza es la que determina las posibilidades de éxito. Incluso la igualación de los medios económicos (a través de becas y/o créditos) para desarrollar los estudios superiores - aunque promueve una igualación formal - no suprime las ventajas / desventajas de origen que quedan veladas por un sistema universitario que premia de manera "neutral" el mérito individual. De esta manera, la generación de una igualdad formal de posibilidades conduciría a una legitimación de los privilegios por parte de la educación.

D esde la perspectiva de Renaut (2008) resulta además prioritario reconocer que aunque la igualdad de resultados constituya un planteamiento utópico e irrealizable, generar condiciones académicas y organizativas para que cada estudiante tenga posibilidades razonables de éxito, constituye sin duda, un avance significativo².

D esde una perspectiva de análisis más abarcativa que integre las nociones de equidad de acceso, participación, aprovechamiento, progreso y culminación de los estudios, una mayor inclusión en la educación superior contribuiría a reducir la desigualdad y a aumentar la cohesión social. Sin embargo, una ampliación de las oportunidades de acceso sin tener en cuenta las diferentes necesidades de los grupos excluidos y sus niveles de rezago en capacidad cognitiva y de conocimiento, constituyen para ellos oportunidades desiguales quetienden a elevar las tasas de deserción y repitencia, limitando las posibilidades de empleo, los niveles de remuneración y la productividad en el mercado ocupacional (Aponte-H ernández, 2008, p. 20).

Por su parte, el diseño y aplicación de políticas públicas inclusivas en la educación superior adquieren además características singulares en los diversos países respondiendo a factores propios de su estructuración social, a las lógicas sobre las que se asientan sus instituciones de educación superior y aun a los procesos ideológicos globales que afectan de manera dispar sus valores e instituciones.

Como regla general, sin embargo, Rawls (1997) sostiene que al formular la política pública se debe aspirar a mejorar el bienestar de aquel que se encuentre en peores condiciones sociales. Es decir, propone maximizar la utilidad mínima en vez de maximizar la suma de la utilidad total de la sociedad. Este criterio denominado maximin implica que el Estado debe aspirar a maximizar el bienestar de la persona que se encuentra peor situada en la sociedad aunque esto por sí mismo no garantice la construcción de una sociedad totalmente igualitaria.

2. Renaut (2008) propone por ejemplo, como "acción positiva" para lograr esta meta: incorporar en los primeros años de estudios asignaturas de cultura general, sobre dominios de la lengua nacional o del inglés como lengua de comunicación internacional, que permita salvar las limitaciones que en términos de capital cultural o escolar presenten los alumnos. 
Por su parte, en opinión de Rosanvallon (1995), el nuevo sentido que se le da a la equidad de oportunidades apunta a lograr una equidad sostenida de las situaciones en el tiempo y no sólo en el punto de partida. Debería avanzarse pues, hacia una equidad de resultados ligada a las variaciones que experimentan las situaciones individuales. En este sentido, la equidad de oportunidades no consiste sólo en compensar en el punto de partida las desigualdades de la naturaleza o las disparidades de fortuna sino que apunta a otorgar - de manera permanente - los medios necesarios para encauzar la vida.

En esta misma sintonía, Bobbio (1993, p.78) sostiene que para situar a individuos desiguales por nacimiento en las mismas condiciones de partida "puede ser necesario favorecer a los más desposeídos y desfavorecer a los más acomodados", esto es, introducir discriminaciones de otro modo no existentes, a los efectos de que, una desigualdad opere como instrumento de igualdad para corregir una desigualdad precedente. De esta manera, "la nueva igualdad es el resultado de la nivelación de dos desigualdades".

En el caso de la educación superior se trata de mejorar la equidad dentro de las instituciones; en el nuevo discurso sobre la educación superior, esto refiere a una política de Estado que asume la preocupación por "la formación común de las mismas competencias y conocimiento considerados básicos para el mejor aprovechamiento futuro de nuevas oportunidades compensatorias o remediales para quienes las necesitan; así como la promoción de innovaciones curriculares, pedagógicas y administrativas orientadas a mejorar las oportunidades de logro escolar a sectores con aprestamiento educativo deficiente" (O rozco Silva, 2006).

Lo que resulta claro, es queel acceso formal a las instituciones ya no constituye un mecanismo satisfactorio de democratización ni inclusión y esnecesario generar condiciones para la permanencia y egreso de los nuevos sectore sociales que acceden al nivel superior sin sacrificar la calidad y excelencia que - se supone el mismo implica.

Políticas de inclusión en la educación superior: las Políticas de Acción Afirmativa (PAA) ${ }^{3}$.

El desarrollo de políticas activas de inclusión, que en algunos países se llaman acción afirmativa (Estados Unidos, América Latina) y en otros, discriminación positiva o acción positiva (Europa), da cuenta de la aplicación de un concepto más dinámico de igualdad, que más allá de los aspectos formales procura efectivamente operar en el plano material o substancial.

3. Para un análisis exhaustivo del debate en torno a las PAA puede consultarse Williams, 2006. 
Estas PAA tienen su origen en los Estados U nidos durante el gobierno del Presidente Kennedy ${ }^{4}$, quien en 1961 las propone a los efectos de enfrentar la discriminación que subsistía a pesar de las leyes de derechos civiles y la garantía constitucional incluida en las enmiendas de fin del siglo XIX. Por entonces, se instruyó a los contratistas federales a tomar acciones afirmativas para asegurar que los postulantes fueran tratados de manera igualitaria en relación a la raza, color, religión, sexo o nacionalidad. En 1964, el Acta dederechosciviles se convierte en ley y, a partir de 1967, las acciones afirmativas se desarrollan también en relación a las mujeres.

La característica central de las PAA es que procuran aproximarse al ideal constitucional de la igualdad material tratando de neutralizar los efectos de los distintos tipos de discriminación que existen en la sociedad para promover una diversidad racial, cultural y sexual que resulte representativa de la sociedad en los ámbitos de la educación y el trabajo. Las acciones afirmativas pueden definirse como un conjunto de políticas públicas y privadas de carácter obligatorio, facultativo o voluntario concebidas para combatir la discriminación racial, de género, de origen nacional o de característicasfísicas, que son implementadas para corregir o mitigar los efectos presentes de una discriminación practicada en el pasado, teniendo como objetivo concretar el ideal de igualdad de acceso efectiva a bienes fundamentales como la educación y el empleo (Gomes, 2003, p. 95) ${ }^{5}$.

Se diferencian de las políticas gubernamentales antidiscriminatorias pues éstas surgen de leyes cuyo contenido es meramente prohibitivo, y ofrecen a las víctimas instrumentos jurídicos de intervención ex post. En cambio, las acciones afirmativas, constituyen un cambio importante en la postura del Estado, el cual, resguardado en una supuesta neutralidad, aplicaba sus políticas sin atender a la incidencia de factores como el sexo, la raza o el color. Se trata pues, de políticas y de mecanismos de inclusión concebidos para concretar un objetivo constitucional universalmente reconocido: el de la igualdad de oportunidades al que todos los seres humanos tienen derecho. La igualdad deja de ser simplemente un principio jurídico a ser respetado por todos, y pasa a ser un objetivo constitucional a ser alcanzado por el Estado y por la sociedad (Gomes, 2003, p. 95).

Se trata sin embargo, de medidas reparatorias que procuran enfrentar los efectos que la discriminación de derecho y de hecho ha generado en grupos

\footnotetext{
4. Sin embargo, las prácticas que proveen beneficios o trato preferencial a individuos por su pertenencia a grupos socialmente postergados, se puede encontrar más tempranamente, bajo diversas formas en una gran variedad de países (Cunninghan, 2002, p. 210).

5. E n Estados Unidos, su desarrollo está asociado al daño causado por un actor cuya actitud hacia otra persona está sesgada por la raza, sexo u origen nacional de la misma, que lo lleva a actuar de una manera discriminatoria (Cunninghan, 2002, p. 21 I).
} 
que experimentaron - durante muchas generaciones - situaciones de sometimiento y exclusión.

En Estados Unidos, a partir del desarrollo de estas políticas, se efectivizó una significativa expansión del porcentaje de negros (entre 18 y 25 años) en la educación superior. Estos pasaron de representar el 13\% del total en 1967 a constituir el 30\% en el año 2000, siendo el momento de mayor crecimiento el que media entre 1967 y $1976^{6}$. Este dato no obstante, es sólo indicativo de los potenciales efectos de las PAA, pues éstas se aplicaron únicamente en algunas universidades (M oehlecke, 2004) ${ }^{7}$.

Estas políticas surgidas en el contexto de la década del 60, fueron objetadas desde el inicio, pero sólo a partir de los 90 son atacadas de manera sistemática, especialmente en los estados de California y Florida. Algunos se oponen por basarse en categorías raciales como negros, afroamericanos o latinos, y sostienen que programas desarrollados usando sólo categorías de clase y focalizando en aquellos que tienen menor renta, serían igual de efectivos y más equitativos. 0 tros sostienen que no todos los afroamericanos necesitan la acción afirmativa en razón de que la heterogeneidad de situaciones es muy amplia8. O tras críticas focalizan en la pérdida de centralidad del mérito y la violación del principio de igualdad ante la ley.

M uy frecuentemente, las PAA se confunden con la implantación de una política de cuotas, cuando en realidad ésta es sólo una de sus posibles formas de operativización, que no agota otras formas de implementación.

Si bien originalmente diseñadas para atender la situación de grupos discriminados a partir de una característica determinada (color, género, discapacidad física, etc), estas políticas - en un sentido amplio - se orientan a todos los grupos excluidos que, más allá de sus características personales e individuales, pueden englobarse en una categoría más abarcativa como la pobreza. En último término habría un reconocimiento de que la pobreza actual, es producto de la discriminación sufrida en el pasado, cuyos efectos se extienden en el presente.

6. Algunos autores señalan sin embargo, que la clase media negra existía en Estados Unidos antes del establecimiento de las PAA. Estas habrían favorecido su expansión, sin mejorar mayormente la situación de los negros pobres (Azevedo, 2004).

7. Un caso paradigmático lo constituye la Universidad de California, la cual en los 60 fue la primera en adoptar criterios de raza para la selección de estudiantes y la primera en abandonarlas en 1995, momento en el cual los porcentajes de representación de los negros en la universidad volvieron a aproximarse a los históricos (Moehlecke, 2004).

8. Algunos sostienen que las PAA sólo deberían aplicarse a quienes reunieran las siguientes características: ser descendientes de esclavos, tener orígenes rurales y del Sur de los Estados Unidos, residencia actual en las ciudades del norte y en ghettos. Para una ampliación de estas posturas puede consultarse Cunningham (2002, p. 212). 


\section{Las cuotas en la educación superior como PAA}

Las cuotas pueden definirse, siguiendo a Domingues (2005), como mecanismos extremos de acción afirmativa que permiten reservar un determinado porcentaje de vacantes para un grupo específico de población, sea para el ingreso a la universidad, al mercado de trabajo 0 a la representación política (cuotas para la representación femenina en cargos electivos, por ejemplo).

Este tema ha merecido una amplia discusión en todos aquellos países en los que se fijó como mecanismo de inclusión de minorías en la educación superior. En este sentido, los debates generados en Brasil en torno a la implantación de cuotas raciales son de una gran riqueza, y aunque en buena medida, responden a una experiencia nacional particular, poseen líneas matriciales dotadas de cierta universalidad.

Los argumentos contra las cuotas son de distinta natural eza pudiendo identificarse al menos cuatro núcleos importantes: algunos están ligados al principio de igualdad ante la ley o sostienen la necesaria primacía del mérito, otros aún discuten a partir de la noción de raza y meztizaje y finalmente algunos rechazan las cuotas pues diagnostican que el verdadero problema reside en la pobreza y la desigualdad, y no en la raza.

1- En efecto, se sostiene, que - en la medida en que la igualdad de todos ante la ley es un principio estructurante de la democracia - las cuotas amenazan el principio de igualdad política y jurídica de los ciudadanos en una república9.

2- Una segunda línea argumentativa se basa en el mérito individual como única vía de acceso a los bienes culturales escasos, como el ingreso a la universidad pública (Rocha Pinto; C lemente Junior, 2004). Esto puede ligarse a la acendrada competitividad que se da a nivel mundial que hace necesario el mantenimiento de altos niveles de excelencia en la educación superior, los cuales podrían verse reducidos con el acceso de aspirantes poco calificados.

3- Además, la sociedad brasileña ha experimentado un alto proceso de mestizaje, que dificulta la definición de quién es negro y quién no lo es. Adicionalmente, la antropología sostiene que las razas no existen por sí mismas, sino que se trata de una construcción ad hoc ${ }^{10}$. Por otra parte, la imposición del

\footnotetext{
9. Argumento incluido por ejemplo en el Manifesto contra as cotas, 2006, firmado por un importante grupo de intelectuales.

10. Eunice Durham sostiene que "o conceito moderno de raça implica em diferentes níveis de concentração de certas características genéticas nos grupos. Conseqüentemente, não existe uma raça pura, que apresente 100\% de determinada característica" (Véase, Classificação racial divide opiniões sobre sistemas de cotas, Folha de Sâo Paulo, 26/7/2006).
} 
sistema de cuotas podría redundar en una acentuación del racismo, en la medida que favorecer a negros e indios podría interpretarse como una discriminación hacia quienes no lo son.

4- 0 tros argumentos focalizan en el hecho de que la desigualdad no debe relacionarse con la raza o el color sino con la pobreza y la exclusión económica, procesos que merecen soluciones universalistas y no particularistas. En este sentido, la expansión de servicios públicos de calidad en áreas especialmente sensibles como la educación, la salud y la previsión social sería una vía mucho más eficiente para actuar contra estos males.

Por lo demás, las cuotas favorecerían a los negros pobres, pero perjudicarían a los blancos pobres, profundizando las diferencias entre ambos grupos. La solución pasaría por desarrollar políticas especiales para todos los pobres, independientemente del color de su piel.

En el otro extremo, quienes apoyan la aplicación de cuotas encuentran en este mecanismo una manera de reparar una herencia de sufrimientos y exclusión que se remonta a la esclavitud. Argumentan que sólo es posible tratar desigualmente a los desiguales, en la medida en que negros, pardos e indios no han sido (ni son) tratados de manera igual a los blancos.

Por otra parte, el éxito el éxito en el ingreso a la enseñanza universitaria no puede explicarse sólo a través de la noción de mérito, en la medida en que los puntos de partida de jóvenes provenientes de distintos espacios sociales, son desiguales, por lo que, el esfuerzo personal, la superación individual de los obstáculos y de la discriminación también deberían ser considerados como "mérito".

Se buscaría también promover la constitución de una elite negra, ya que los miembros de la elite (intelectual, económica, etc) son en su mayoría blancos. Silva dice: "La universidad es la divisoria de aguas en una sociedad racialmente dividida donde el criterio para la incorporación de las clases profesionales también es el criterio de exclusión social. Hasta que no exista una clase media profesional negra, con dominio de los mismos códigos y competencias de la elite, no habrá combate efectivo a la discriminación racial" (apud Rocha Pinto; Clemente Junior, 2004).

\section{Políticas de inclusión en la educación superior en Argentina y Brasil}

Las políticas inclusivas desarrolladas en el ámbito de la educación superior han adquirido características singulares en los diversos países de la región. En algunos, se han aplicado en las instituciones ya existentes mientras en otros se optó por la creación de establecimientos nuevos. Por otra parte, en el primer caso pueden citarse varios mecanismos alternativos: (a) apoyo económico a 
estudiantes carenciados, (b) políticas de acción afirmativas, que a menudo se operativizan a través de cuotas para ciertos grupos que experimentan 0 experimentaron algún tipo de discriminación, (c) creación de cursos especiales destinados a esos grupos.

En otros países en cambio, se ha optado por la creación de nuevas instituciones, constituyéndose en al gunos casos, sistemas paralelos de educación superior. Este es el caso por ejemplo de Venezuela, país en el que se desarrolló en los últimos años una agresiva política de creación de instituciones orientadas a atender a estudiantes provenientes de sectores sociales desfavorecidos que no habían sido seleccionados para ingresar en los establecimientos tradicionales (C hiroleu, 2009). En otros casos se crean instituciones de carácter étnico (universidades indígenas) para atender a estudiantes de ese origen, práctica que se está desarrollando en M éxico y en los países andinos.

Las políticas implementadas en Argentina y Brasil se pueden insertar en la tipología de países que desarrollan diversos mecanismos de inclusión dentro de las instituciones ya existentes.

\section{I El caso argentino}

La estructura social argentina presentó durante buena parte del siglo XX algunos rasgos singulares que la distinguen en el contexto de América Latina. Entre ellos, la temprana conformación, el tamaño y la composición de sus clases medias, la acentuada movilidad social ascendente, la cohesión social y reducidos bolsones de pobreza considerados por entonces, como un fenómeno marginal. (Chiroleu; D elfino, 2007).

A partir de mediados de la década del 70 sin embargo, uno a uno, estos rasgos singulares fueron desmoronándose en la medida en que las transformaciones estructurales introducidas por el último gobierno militar (1976-1983) generaron un fuerte deterioro de las condiciones sociales y una ruptura del tejido social que se iría profundizando en el transcurso de los gobiernos democráticos posteriores, especialmente la gestión neoliberal que, en los años 90, lideró Carlos M enem.

La sociedad que emerge en el siglo XXI se encuentra fuertemente fragmentada en grupos que ocupan posiciones polares en la pirámide social, aunque muchos de ellos continúan considerándose como parte integrante de las clases medias. En este contexto, la pobreza gana centralidad incluyendo, según datos del primer semestre de 2007, alrededor del 23\% de la población. El universo de los pobres por otra parte, se ha heterogeneizado, especialmente a través de la expansión del segmento de los denominados "nuevos pobres", clases medias en proceso de pauperización absoluta. 
En lo que respecta al SES ${ }^{11}$ la Tasa Bruta de Escolarización Superior (TBES) alcanzaba en 2006, el $47 \%$ de la población entre 18 y 24 años ${ }^{12}$. Por su parte, el mapa actual de la educación superior da cuenta de una fuerte diversificación en términos institucionales aunque la presencia de la oferta estatal sigue siendo dominante: la misma cubre el $68 \%$ de la matrícula en educación superior y el $86 \%$ de la universitaria. Sin embargo dentro de las instituciones universitarias, las de gestión privada presentan en los últimos años tasas más altas de crecimiento ${ }^{13}$ y en términos de educación superior, la matrícula del subsector no universitario crece más que la del universitario.

Por otra parte, a partir de 1983, con el retorno a la democracia, la modalidad de acceso más extendida en las universidades públicas argentinas, es el ingreso directo, con el sólo requisito de la obtención del diploma de estudios medios ${ }^{14}$. Es de destacar que este cambio de la política de ingreso se dio sin mediaciones y sin la generación de condiciones mínimas para contener la fuerte expansión de la matrícula que se dio especialmente en la última mitad de la década del 80.

Este sistema, formalmente abierto, supone sin embargo, instancias de selección en el transcurso de las carreras. D e hecho, la tasa de abandono durante el primer año se aproxima al 50\%.

En lo que respecta a las universidades privadas, se da por lo general algún examen de ingreso que según los casos asume un carácter selectivo o el sentido de un diagnóstico general de los ingresantes. En cuanto a las instituciones no universitarias, la heterogeneidad es el rasgo dominante, en la medida en que, por pertenecer a las jurisdicciones provinciales, quedan libradas a la normativa que las mismas establezcan. Sin embargo, el nivel de exigencias en el momento del acceso, suele ser bajo.

Un análisis del caso argentino permite interpretar que el ingreso directo a la mayor parte de las instituciones de educación superior públicas, junto a la gratuidad de las mismas son factores considerados por sí mismos políticas inclusivas latus sensus, mientras los Programas de Becas, que podrían constituir una política inclusiva strictus sensus, adquieren un carácter complementario de

11. En ambos casos sólo focalizaremos en unas pocas variables, como la cobertura, la estructura del sistema y las políticas de acceso a la educación superior.

12. Si se toman en cambio los parámetros OCDE (población escolarizada entre 20 y 24 años), la TBES se ubica en el orden del 66\%. (SPU, 2006).

13. Las instituciones de gestión estatal crecen a un promedio anual del 0,9 mientras que las de gestión privada lo hacen al 8, I (SPU, 2006).

14. No obstante, a partir de esa fecha, algunas instituciones o dentro de ellas, algunas unidades académicas, han adoptado distintas modalidades selectivas. La Universidad de Buenos Aires por ejemplo, organiza el Ciclo Básico Común que es la forma a través de la cual se accede a las carreras de grado. 
aquellas y como tales, ocupan un lugar secundario en el contexto general de las políticas sectoriales. En este caso, el principio rector es la generación de iguales oportunidades para el acceso al tercer nivel (Chiroleu, 2009).

Es a partir de 1996 en el transcurso de un gobierno peronista de corte neoliberal que desarrolla una ambiciosa reforma de la educación superior, cuando se establecen dos programas importantes de apoyo económico a los estudiantes universitarios ${ }^{15}$ : el Programa $\mathrm{N}$ acional de Becas U niversitarias (PN BU) orientado a estudiantes de universidades nacionales que provienen de hogares en situación de pobreza estructural y tienen buen rendimiento académico y el Programa de Créditos para la Educación Superior ${ }^{16}$ alternativa de financiamiento a estudiantes que coyunturalmente atraviesan una situación económica crítica pero pueden garantizar el reintegro del préstamo (Crovetto, 1999, p. 209).

Estos programas, sostienen sus gestores, se basan en el principio de equidad y procuran garantizar a cada individuo que no habrá discriminaciones que restrinjan sus posibilidades de actuar. Por otra parte, el Programa de Becas se piensa como una forma de favorecer la cohesión social al incentivar el acceso y la permanencia en el nivel educativo de alumnos de escasos recursos económicos. Se procura promover también la calidad en los estudios a través de la exigencia de un buen desempeño académico y regularidad en los estudios (Amaro; Araujo, 2003, p. 97).

A partir del año 2000, con la incorporación de los subprogramas para discapacitados e indígenas ${ }^{17}$, se intenta reducir los efectos derivados de otro tipo de desigualdades - como la discapacidad y la discriminación étnico-cultural - que ubican a muchos estudiantes en condiciones de vulnerabilidad en el sistema universitario (SPU, 2005, p. 235).

Los requisitos para postularse para la obtención de la Beca son de edad (menores de 30 años), de regularidad en los estudios, promedio (7 o superior a $7^{18}$ ), y de ingresos familiares (actualmente éstos deben ser menores de \$2.520). En cuanto al monto que se percibe, a partir de 2002, es de $\$ 2500$ anuales pagados en cuotas mensuales ${ }^{19}$.

\footnotetext{
15. Éstos surgen de manera paralela a la profundización de la discusión sobre el arancelamiento de los estudios universitarios y el ingreso selectivo.

16. Este estuvo vigente entre 1996 y 2000. La última convocatoria fue realizada en 1999 y se efectivizó en el año 2000, restringida a la renovación de créditos. A partir de esta fecha el programa concentró sus acciones en el rediseño del sistema de créditos universitarios y en la recuperación de la cartera de deudores

17. En 2006, los subprogramas para indígenas y discapacitados absorbieron respectivamente el $1 \%$ y el $0.6 \%$ de las becas otorgadas.

18. Para la renovación de la beca se solicita tener promedio 6 o superior en las asignaturas aprobadas en la universidad. Hasta 2007 se requería un promedio de 7 o superior.

19. Hasta 200 I eran $\$ 3000$ pagados en 10 cuotas.
} 
En lo que respecta a las características socioeconómicas de los becarios, en 2005, algo más del $10 \%$ pertenecían a familias indigentes, y el $36 \%$ a familias pobres. Por otra parte, si focalizamos en el nivel de instrucción de los padres, según datos 2007, el 35\% tenía estudios primarios, el $42 \%$ estudios secundarios y el $23 \%$ estudios terciarios o universitarios (SPU, 2006, p. 180). Esto supone una cierta primacía en la franja que cubre el sistema de becas del segmento denominado "nuevos pobres", es decir, sectores medios empobrecidos.

Con relación al funcionamiento del Programa de Becas pueden hacerse diversos comentarios. En primer lugar, cabe destacar que supone el reconocimiento de un problema de creciente importancia, como las dificultades económicas de muchos alumnos en el desarrollo de los estudios universitarios. Asimismo, está avalado porque los buenos resultados académicos obtenidos por los becarios son promisorios ${ }^{20}$. Sin embargo, en términos del propio funcionario que desarrolló el Programa a mediados de los años 90 (Crovetto, 1999, p. 216), existe una "enorme brecha" entre la oferta y la demanda, lo que impone un nivel de exigencias muy alto para acceder a la obtención de una beca. De hecho, éstas atienden sólo al 0,5\% de la matrícula total, y cubren apenas al $22 \%$ de los demandantes ${ }^{21}$.

A fines de 2008, además, se anunció la creación del Programa de Becas Bicentenario destinado a estudiantes provenientes de hogares de bajos ingresos y que sean aspirantes a carreras universitarias o tecnicaturas científico-técnicas, en las ramas de las $\mathrm{C}$ iencias $\mathrm{N}$ aturales, $\mathrm{C}$ iencias Agrarias, Ciencias A plicadas y Exactas, e Ingenierías. Existe además un Programa de Becas para Carreras de Grado en áreas TICS. Por estas vías se procura elevar la matrícula en carreras consideradas estratégicas para el país, y simultáneamente actuar en términos de equidad social.

En 2009 se otorgarán 30 mil becas que insumirán un presupuesto de \$145 millones y los alumnos beneficiados recibirán por año, diez cuotas mensuales de $\$ 500$. Se prevé mejorar el rendimiento académico de los becarios a través de acciones complementarias que abarcarán el desarrollo de cursos de nivelación, el fortalecimiento de condiciones de base de los alumnos y el acompañamiento de los becarios a lo largo de toda su trayectoria.

El Programa de Becas Bicentenario constituye un proyecto de gran envergadura por la inversión económica que supone, implica la jerarquización de ciertas carreras consideradas vitales para el desarrollo nacional y por otra parte,

20. Al respecto, demoran menos que el promedio para obtener su diploma, y el $60 \%$ de los mismos tiene un alto rendimiento académico en términos de calificaciones obtenidas (SPU, 2006).

21. Esta situación viene repitiéndose desde el primer año de establecimiento del Programa. Por ejemplo, en 2006, se presentaron 29. 142 candidatos, de los cuales 15.442 reunían los requisitos solicitados, pero sólo fueron aprobados 6.966 y finalmente se adjudicaron 6.528 becas. 
por primera vez se plantea la necesidad de hacer un seguimiento a los beneficiarios no sólo en el plano económico sino también en el plano académico.

\subsection{El caso de Brasil}

En el caso de Brasil merecen enfatizarse los rasgos jerárquicos de su sociedad y la distancia social que demarca con nitidez la posición de las distintas clases. A partir de 2001, opera una lenta mejoría en la distribución de la renta, fruto especialmente de los programas sociales generados por el gobierno Lula ${ }^{22}$, que va acompañada por una tenue reducción de la pobreza y una mayor caída de la indigencia.

D esde principios del siglo XX, la movilidad social fue intensa, aunque se caracteriza como de corta distancia, esto es, muchos ascienden poco, y pocos ascienden mucho, lo que genera un estiramiento de la estructura social por la coexistencia de mucha movilidad y alta desigualdad. En la actualidad, como consecuencia del aumento de la competitividad del mercado de trabajo, la movilidad se vincula a las calificaciones y competencias educativas (Pastore; do Valle Silva, 2004).

A pesar de estos datos sociales promisorios, todavía subsisten rasgos estructurales preocupantes, entre los cuales las desigualdades generadas por cuestiones de color y raza, ocupan un lugar importante.

- Sobre algo más de 14 millones de analfabetos, 10 millones son negros y pardos; las tasas de analfabetismo para personas de 15 años y más fueron del orden del 6,5\% entre los blancos y del $14 \%$ entre los negros y pardos.

- Si se focaliza en el porcentaje de población entre 18 y 24 años que cursa estudios superiores, lo hace el $56 \%$ de los blancos y el $22 \%$ de los negros y pardos. Para 1996, este dato era respectivamente del $30.2 \%$ y el $7.1 \%$, lo que evidencia, no obstante, una importante mejoría.

- Si tomamos al segmento de población mayor de 25 años que tiene estudios superiores completos, en 2006, éste constituía sólo el $8.6 \%$ de la población total, y estaba conformado por un $78 \%$ de blancos, un $3.3 \%$ de negros y un $16.5 \%$ de pardos.

- Con relación a la apropiación de la renta nacional, la distribución entre el $10 \%$ más pobre y el $1 \%$ más rico revelaba que en 2006 los blancos representaban el $26 \%$ de los más pobres y el $86 \%$ de los más

22. Al respecto, resulta especialmente efectivo el Programa Bolsa Familia; sin embargo, aunque de menor incidencia deben destacarse además la mayor cobertura educacional, la reducción del desempleo y el aumento del salario mínimo y de las jubilaciones y pensiones. 
ricos. Los negros y pardos representaban por su parte, el $73 \%$ de los más pobres y el $12 \%$ de los más ricos (IBGE, 2007).

En lo que respecta a la educación superior, la TBES abarcaba en 2006 al $12 \%$ de la población entre 18 y 24 años ${ }^{23}$, lo que implica que aún se inscribe en el modelo de educación superior de elite. EI SES por su parte, es extremadamente heterogéneo y se halla profundamente diversificado y segmentado. En este caso, el rasgo dominante es la privatización, tendencia que si bien se manifiesta tempranamente, se exacerba a mediados de los años 90 . En 2006, sólo el $10 \%$ de las instituciones de educación superior era de carácter público y contenían el $27 \%$ de la matrícula total. Un $55 \%$ de ésta asiste a la universidad y las de carácter público atienden el $42 \%$ de la matrícula universitaria.

En los últimos años, el acceso a la educación superior ha adoptado diversas modalidades. Sin embargo, el Vestibular constituye una modalidad ampliamente extendida y aceptada socialmente para el ingreso a la educación superior tanto pública como privada; no obstante, se reconoce que este mecanismo actúa como forma de selección social pues el nivel de exigencia de las instituciones públicas (y algunas privadas) sólo puede ser alcanzado por alumnos con una buena formación de nivel medio y preparación ad hoc: en ambos casos, esto se concentra en los sectores socialmente más favorecidos que asisten a escuelas medias privadas. Actualmente, el Vestibular coexiste con otras modalidades como la Evaluación seriada de la Enseñanza M edia o los resultados obtenidos en el Examen $\mathrm{N}$ acional de Enseñanza $\mathrm{M}$ edia, los cuales en al gunos casos se combinan con aquél24.

En el año 2006 se ofrecieron algo más de 2.6 millones de vacantes para atender una demanda de más de 5.2 millones de candidatos. Finalmente cubrieron los distintos requisitos de admisión casi 1.4 millones de aspirantes. Sin embargo la relación número de aspirantes por vacante es claramente diferente entre el sector público y el privado: en el primero, el promedio es de 7,3 candidatos mientras en el segundo es de 1,3 (MEC /INEP, 2006).

D esde mediados de la década pasada se han venido desarrollado diversas políticas de inclusión en la educación superior, algunas de las cuales procuran atender las desigualdades socioeconómicas a través del otorgamiento de becas 0 créditos mientras otras están más focalizadas hacia las desigualdades raciales y étnicas (PAA).

23. Si se adopta en cambio los parámetros OCDE, la tasa apenas supera el $18 \%$ en el mismo año.

24. Se han desarrollado varias opciones que tratan de lograr una inclusión social más amplia en las universidades, como por ejemplo los cursos pre-vestibulares alternativos (o populares), los programas de cuotas, y los de interiorización. Para una profundización de esta temática puede consultarse Peixoto, 2008. 
Asimismo se crearon cursos especiales en las instituciones tradicionales, dirigidos a ciertos grupos y orientados por ejemplo a la formación de maestros y profesores. 0 tras formas de inclusión apuntan a la creación en 2006 de la Universidad Abierta de Brasil (UAB), institución orientada especialmente a la formación de profesores para la educación básica y formación continua para aquellos que ya ejercen esos cargos, que el $\mathrm{M}$ inisterio calcula tendrá, a principios de 2009, alrededor de 100 mil alumnos ${ }^{25}$.

D esde su llegada al gobierno en 2003, la educación superior ha ocupado un lugar privilegiado en la agenda de gobierno del Presidente Lula, el cual queda reflejado en la cantidad de iniciativas legislativas y proyectos impulsados en los seis años de gestión. Las políticas se articulan en torno a la necesidad de expandir la TBES, reducir las desigualdades sociales que caracterizan al sistema educacional e introducir mecanismos destinados a la promoción e inclusión social y étnico-racial en el nivel superior (Peixoto, 2008). En este sentido, se han desarrollado medidas en el sector público y privado.

En lo que respecta al primero, se han encarado programas de expansión de la oferta pública y a partir de 2007 se establece el Programa de Reestructuración y Expansión de las Universidades Federales (REU NI) el cual tiene entre otros objetivos la creación de condiciones para la expansión de las vacantes en estas instituciones. Se inscribe en este sentido en el Plan de D esarrollo de la Educación presentado por el gobierno ese mismo año y se articula con el Plan $\mathrm{N}$ acional de Educación del año 2001 que presentaba como meta alcanzar en 2010 la escolarización en el nivel superior del $30 \%$ de la población de entre 18 y 24 años. En la presentación del Programa, se señala el agotamiento de la vía privada como forma de expansión de la matrícula y la necesidad de que sea la educación superior pública la que atienda la gran demanda que se ejerce sobre el tercer nivel (M EC, 2007, p. 7).

Las universidades federales deben presentar proyectos que contemplen especialmente tres aspectos: flexibilidad curricular, apoyo para la formación pedagógica de los docentes que permita el desarrollo de prácticas pedagógicas modernas y el uso de tecnología y el desarrollo de mecanismos de inclusión que permitan al canzar la igualdad de oportunidades en el acceso y la permanencia en las instituciones (M EC, 2007, p. 10) ${ }^{26}$.

25. La meta fijada por el Ministerio es que para 20 I2, la UAB reúna alrededor de 600 mil alumnos en todo el país.

26. Por ejemplo, en 2008, la Universidad Federal de Sergipe que adhiere al Programa y por consiguiente recibe fondos especiales, había ya aumentado en un $40 \%$ sus vacantes para el ingreso incluyendo vacantes en el turno noche, mejorado la cobertura de todas las vacantes, el equipamiento e infraestructura disponible y la contratación de 400 docentes de dedicación exclusiva y personal administrativo (Josué Modesto dos Passos Subrinho, Reuni na expansâo da UFS, 04/03/2009, http://www.ufs.br/reuni/. 
El Programa al que adhirieron todas las universidades federales, se propone alcanzar en un plazo de cinco años una tasa de graduación del $90 \%$ en los cursos de grado y una relación de dieciocho alumnos de graduación por docente $^{27}$. Sus críticos destacan especialmente la celeridad con la que se está dando la expansión, la cual puede redundar en una pérdida de calidad del sector y una sobrecarga de trabajo para los docentes.

Por otra parte, desde 2003 se construyeron 48 campi y 10 universidades distribuidas en todo el país, que permitieron una expansión del $25 \%$ de la oferta de educación superior pública, profundizando además el proceso de interiorización de la educación superior.

En otro orden de cosas, en algunas universidades estatales se implementa un sistema de cupos para negros e indios, mecanismo de acción afirmativa que reserva un porcentaje de las vacantes para personas pertenecientes a ciertos grupos raciales o étnicos. Asimismo, el Congreso $\mathrm{N}$ acional está discutiendo un proyecto de ley que garantiza el $50 \%$ de las vacantes en las instituciones públicas para alumnos provenientes de escuelas públicas y efectúa una reserva de cupos para minorías étnicas (Peixoto, 2008).

Sin embargo, las políticas de inclusión de mayor envergadura han sido dirigidas hacia las instituciones privadas: entre ellas, el Programa de Financiamiento estudiantil (FIES) y el Programa Universidad para todos (PROUNI).

EI FIES está destinado a financiar los estudios superiores de alumnos que ya se encuentren regularmente matriculados en instituciones no gratuitas y que tienen dificultades para sufragar los costos de su formación. Se trata de un crédito que cubre parcialmente la cuota y que deberá ser devuelto al finalizar la carrera con un interés anual de entre el 3.5\% y el $6.5 \%$ según se trate o no de carreras priorizadas por el M inisterio, como por ejemplo la formación de profesores.

Creado en 1999 sobre la base del Programa de Crédito Educativo, el FIES ha experimentado en estos años un fuerte crecimiento tanto en número de instituciones incluidas en el Programa como de estudiantes.

Por su parte, el PROUNI, establecido en 2004, prevé aprovechar parte de las vacantes ociosas de las Instituciones de Enseñanza Superior Privadas a través de becas de estudio integrales y/o parciales para estudiantes considerados pobres (con un ingreso familiar menor a tres salarios mínimos), que cursaron el nivel secundario en escuelas públicas, con una participación de indígenas y negros similar a la que se da en cada estado y a profesores de la red pública de

27. Para el período 2008-20 I I se proyecta una inversión del orden de los 2 billones de reales (MEC, 2007, p. II). 
enseñanza fundamental que no tengan diploma de enseñanza superior. Como contrapartida, las instituciones privadas (con o sin fines de lucro) que adhieran al programa, serán eximidas del pago del impuesto a la renta y de la contribución social sobre la ganancia líquida.

En Brasil, más del 10\% de la matrícula total (cerca de 450 mil alumnos) tiene acceso a al gún tipo de beneficio y el PRO U N I supone una fuerte inversión (4.500 millones de reales). Existe además un proyecto para pasar los fondos del FIES al PROUN I para ampliar a 700 mil los alumnos beneficiados con el financiamiento.

Por vía del PRO UNI el gobierno aspira a abrir alrededor de 300 mil vacantes en los próximos años ${ }^{28}$ y llegar a 500 mil antes del final del mandato del Presidente Lula.

Sin embargo, en 2007, este Programa no pudo cubrir el $10 \%$ de las vacantes ofrecidas, especialmente en los casos en que se otorgaban becas parciales para solventar la mitad del arancel total. El Programa también asigna cuotas raciales, y precisamente estas vacantes son las más difíciles de cubrir pues negros e indígenas forman parte de los estratos socialmente más desfavorecidos, que carecen de recursos para afrontar los gastos de una carrera de grado ( $C$ atani; H ey, 2007).

$\mathrm{H}$ a sido intenso el debate generado en torno a este Programa; para algunos autores (C orbucci, 2004) constituye una iniciativa de redistribución indirecta de la renta en la medida en que, a través de la exención fiscal, se benefician los estratos populares más pobres, mientras que si la recaudación se efectivizara, esos recursos no necesariamente se orientarían hacia esos grupos.

D esde otro punto de vista se señala que si bien el objetivo declarado por el gobierno es la ampliación del acceso al nivel superior, ésta se desarrolla sin una inversión directa por parte del gobierno ${ }^{29}$ y se teme que la modalidad escogida podría profundizar el proceso de privatización de la educación superior brasileña. Aunque el Programa no significa una menor presencia estatal, implicaría la reconfiguración de la oferta de enseñanza superior (M ancebo, 2004, p. 853) y el fortalecimiento del sector privado. Al respecto, algunos lo relacionan con la falta de viabilidad de muchas instituciones privadas que encontraron límites estructurales vinculados con la capacidad adquisitiva de su clientela (Carvalho, 2006).

D esdela perspectiva social, al gunos autores sostienen que tiende a profundizar la desigual distribución de los bienes educacionales y la segmentación del sis-

28. Para el primer semestre de 2009 se ofertaron alrededor de 156 mil becas.

29. El gobierno renuncia a cobrar 50 millones de reales en impuestos, pero la creación de estas vacantes en las instituciones publicas insumiría alrededor de 350 millones. 
tema, orientando de manera irreversible a los sectores más pobres a estudiar en instituciones de baja calidad, que son las que ofrecen las vacantes. Por otra parte, cabe poner en duda la propia eficacia del programa ${ }^{30}$ en la medida en que la población carenciada, no sólo requiere cursos gratuitos, sino una cobertura de los gastos de transporte, residencia, alimentación y salud, aspectos que sólo cubren las instituciones públicas (M ancebo, 2004; Carvalho, 2006) ${ }^{31}$.

D esde otra perspectiva, Simón Schwartzman (2004) - académico ligado a las reformas de corte neoliberal de los 90 - alerta sobre la posibilidad de que esta apertura derive en la pérdida de calidad de las instituciones por el ingreso de personas que no están adecuadamente preparadas.

A partir de 2004 se inició el Programa de A poyo el mplantación del desarrollo de Cursos para la Formación de Profesores Indígenas (PRO LIN D). Su objetivo general es conformar un programa integrado de apoyo a la formación superior de profesores que enseñarán a los indígenas, considerando que ésta constituye una política pública del estado nacional a ser implementada por las instituciones federales y de los estados de educación superior de todo el país ${ }^{32}$.

En junio de 2008 se establece como objetivo específico del Programa, apoyar los proyectos de cursos en el área de las Licenciaturas Interculturales para formar profesores para la docencia en el segundo tramo de la educación básica y la educación media de las comunidades indígenas, en consonancia con la realidad social y cultural de cada pueblo.

Como puede apreciarse, las políticas de inclusión implementadas durante la gestión de Lula son vastas y complejas y se componen de medidas orientadas al sector público y al privado, aunque con primacía de este último, y abarcan tanto cuestiones relativas al acceso como a la permanencia en los estudios superiores. Aunque difícilmente se logre para 2010 alcanzar la meta del 30\% de TBES, y aunque puedan discutirse muchas de las medidas implementadas, es notorio el esfuerzo asumido por el ejecutivo para ampliar la oferta en términos cuantitativos y la representación social de sectores tradicionalmente ausentes de la educación superior.

30. Dias Sobrinho y De Brito (2008, p. 502) señalan sin embargo, que según estudios recientes, los alumnos incluidos en el PROUNI han obtenido mejores resultados académicos que el resto de los estudiantes.

31. A partir de 2006, el Ministerio también otorga becas de permanencia para cubrir algunos de los gastos de los alumnos que recibieron becas integrales. Sin embargo, éstas cubren aún un porcentaje muy reducida de los candidatos.

32. En 2008, el Programa recibió alrededor de 5 millones de reales y hay 12 instituciones seleccionadas para la implementación del mismo. 


\section{Consideraciones finales}

Las políticas inclusivas se desarrollan en diversos países, aunque sus alcances conceptuales y de cobertura son diferentes en cada uno de ellos. Por ejemplo en el caso europeo, existe en general un explícito rechazo de las PAA ${ }^{33}$ aunque sí se reconoce la necesidad de favorecer el acceso de los mayores de 25 años, con 0 sin estudios superiores anteriores. Esta situación parece centrarse en las demandas que se originan en un contexto internacional fuertemente competitivo y en la necesidad de lograr una adaptación permanente de la fuerza de trabajo a los nuevos avances de la tecnología (Teichler, 2006, p. 79).

En los Estados Unidos se dio durante varias décadas una combinación entre PAA y una fuerte diversificación de la educación superior, aunque promediando los 90, las primeras fueron retrocediendo en un contexto de creciente rechazo.

En América Latina, la región más desigual del planeta, la discusión sobre la inclusión es reciente, y el desarrollo de PAA lo es más aún. Pero, ¿cuáles deberían ser los alcances de la noción de inclusión en la educación superior? Resulta evidente que - siguiendo a Rosanvallon - la igualdad de oportunidades no puede agotarse en la compensación que se efectúa en el punto de partida, sino que debe sostenerse en el tiempo, brindando los medios necesarios para lograr/ propender a la igualdad de resultados.

En este sentido, Ias PAA son acciones remediales tendientes a enfrentar las discriminaciones de hecho 0 de derecho que experimentan ciertos grupos. A pesar de que no proponen transformaciones estructurales ni van mucho más allá de "generar condiciones para el acceso", algunos las rechazan en nombre de la igualdad de oportunidades y el mérito. Esto acontece especialmente en el ámbito universitario.

Sucede sin embargo, que la igualdad de oportunidades no garantiza iguales resultados que sean independientes del punto de partida individual y que el mérito no es un valor de contenido único e indiscutible que no experimente interferencias del ámbito social: su construcción responde al modelo hegemónico, y no admite desviaciones ni la introducción de matices. Sin embargo, en situaciones socialmente adversas, el mérito zadquiere la misma connotación que en los casos de los hijos de la elite? ¿Se puede reclamar el mismo nivel de cumplimiento a todos los alumnos, independientemente de su procedencia, capital cultural, social, económico?

Consideramos con M oehlecke (2004), que el mérito puede conceptualizarse en estos casos, como la capacidad que tienen los estudiantes que se encuentran

33. Teichler (2006, p. 79) señala que existe consenso respecto a que, para balancear desigualdades previas, deben reducirse las barreras financieras, así como desarrollar medidas compensatorias desde el jardín de infantes hasta la escuela secundaria superior. 
en condiciones adversas para superar las dificultades a través del esfuerzo personal, aunque los resultados no sean los mismos que los de los estudiantes en situaciones más favorables. Esto es, "el mérito concebido como medida justa del empeño de cada uno". Esto no supone sin embargo, alcanzar saberes de menor calidad, sino recibir un tratamiento que permita compensar los déficits y por esa vía también las diferencias.

Sin embargo, la forma disímil en que en Argentina y Brasil se enfrenta la ampliación de la inclusión en la educación superior, merece relacionarse con factores estructurales de los respectivos sistemas, como la elevada cobertura que el nivel ya alcanzó en Argentina a partir del desarrollo del sector público, y en el caso de Brasil a partir de la expansión tardía y aún incompleta de la matrícula superior - prioritariamente - a través del sector privado. En este contexto, ambos países desarrollan políticas públicas - de diferente alcance y envergadura - destinadas a encuadrar su diagnóstico sobre la temática y a contener su propuesta de inclusión de nuevos grupos, tradicionalmente postergados en el ámbito de la educación superior.

Constituyen dos diseños al ternativos de políticas de inclusión en la educación superior que autorizan a constatar un dispar compromiso y una diferente jerarquización de las mismas que si bien puede asociarse a las diferencias en términos de cobertura y al peso que el subsector público tiene en cada país, da cuenta también de una singular manera de propender a la ampliación de las bases sociales de la educación superior.

En ambos casos, se procura especialmente ampliar el acceso al nivel, y sólo recientemente se ha insinuado la incorporación de mecanismos que procuran obtener una mayor equidad en términos de resultados. En este sentido, la experiencia argentina permite adelantar que garantizar sólo el acceso a las instituciones no supone por sí mismo una ampliación de la representación de los sectores sociales menos favorecidos entre los graduados. De hecho, en este caso, la magnitud de la cobertura que alcanza el nivel debe leerse de manera conjunta con las bajas tasas de graduación y las elevadas tasas de deserción, especialmente en el primer tramo de las carreras.

Al respecto, la diversidad de puntos de partida en el espectro social constituye un dato insoslayable si el objetivo es profundizar la democratización externa del nivel superior, y trae aparejada la necesidad de pensar en compensaciones permanentes para que los sectores más postergados alcancen los resultados favorables, en términos de graduación y de excelencia, que una institución del tercer nivel debe reclamar. El mérito tiene socialmente diferentes alcances, y no puede pretenderse la aplicación de un concepto homogéneo que ignore las diferencias sociales. 
En lo que atañe a las políticas concretas, las mismas están escasamente jerarquizadas en Argentina en términos de presupuesto asignado y nivel de cobertura lo cual lleva a suponer que continúa atribuyéndose al ingreso directo efectos democratizadores de amplio alcance. En el caso de Brasil, la inversión y el nivel de cobertura son muy importantes, aunque la concreción de una parte significativa de las políticas se ejecute a través de instituciones privadas, en muchos casos de dudosa calidad, lo que podría atenuar sus efectos democratizadores.

Si bien estas políticas constituyen un pequeño avance, queda por evaluar sus efectos individuales y sociales para actuar sobre los desajustes 0 desviaciones que se presentan en la práctica. La propuesta además, no puede agotarse en el acceso y debe necesariamente orientarse a alcanzar una mayor equidad en términos de resultados para poder pensar que iniciamos el largo y complejo camino hacia una mayor inclusión social.

\section{Referencias bibliográficas}

APO NTE-H ERN ÁN DEZ, Eduardo. D esigualdad, inclusión y equidad en la Educación Superior en América Latina y el $C$ aribe: tendencias y escenario alternativo en el horizonte 2021. In: CO N FEREN CIA REGIO N AL DE ED U CACIÓ N SU PERIOR, 2008. Cartagena. Tendencias de la educación superior en América Latina y el Caribe.Disponible en: «tttp:// www.cres2008.org/es/info_documentos.php>. Consultado el: 22/5/2008.

AZEVED O, CeliaM ariaM arinho de. Cota racial eEstado: abolição do racismo ou direitos de raça?CadernosdePesquisa, São Paulo, v. 34, n. 121, 2004. D isponibleen: http://www.scielo.br/ scielo.php?script=sci_arttext\& pid=S0100-15742004000100010. Consultado el: 22/6/ 2008

AM ARO , Jorge; ARAUJO, Analía. ProgramaN acional deBecas U niversitarias. In: PU GLIESE, Juan $\mathrm{C}$ arlos(Ed.). PolíticasdeEstado para la universidad argentina. Buenos Aires: M inisterio de Educación, Cienciay Tecnología, Secretaría dePolíticas Universitarias, 2003.

BO BBIO , N orberto. I gualdad ylibertad. Barcelona: Paidós, 1993.

BO U RD IEU, Pierre; PASSERO N, Jean-Claude. Loshereder os los estudiantes y la cultura. Buenos Aires: Siglo Veintiuno, 2006. (Primera edición en francés, 1964).

CARVALH O , Cristina H elenaAlmeida de. 0 Prouni no governo Lula eo jogo político em torno do acesso ao Ensino Superior. Educação eSociedade, Campinas, v. 27, n. 96, 2006.

CATAN I, Afranio M endes; H EY, Ana Paula. A educação no Brasil eastendências das políticas deampliação do acesso. In: EN CUENT RO N ACIO N AL, 5. y LAT IN OAM ERICAN O LA UN IVERSID AD COM O O BJETO DE IN VEST IGACIÓ N , 2., 2007, Tandil: 30 y 31 de agosto y 1 을 de septiembre de 2007.

CORBU CCI, Paulo Roberto. Financiamento edemocratização do acesso à educação superior no Brasil: da deserção do Estado ao projeto dereforma. Educação eSociedade, v. 25, n. 88, 2004. 
CRO VET TO, N orberto. Becas y créditos estudiantiles como instrumentos para fortal ecer la equidad. In: SÁN C H EZ M ART I N EZ, Eduardo (Ed.). La Educación Superior en la Argentina: transformaciones, debates, desafíos. BuenosAires: M inisterio deCulturay Educación, Secretaría dePolíticas Universitarias, 1999.

CUN N IN G H AN , Clark D. Affirmative action: comparative policies and controversies. International Encyclopedia of theSocial and Behavioral Sciences, 2002. D isponibleen: «ttp:/ /law.gsu.edu/Equality/EncyclopediaArticle.pdf>. Consultado el: 12/01/2008.

CH IRO LEU Adriana; D ELFIN 0 , Andrea. Estructura social y desigualdades de género: la situación delasmujeresen laArgentinadeprincipios desiglo. In: CARBO N ERO GAM U N DI, M aría Antonia; LEVIN , Silvia(Ed.). Entrefamilia y trabajo: relaciones, conflictosy políticas de género en Europa y América Latina. Rosario: $\mathrm{H}$ omo Sapiens, U niversitat deles Illes Balears, D ept. deFilosofíai Treball Social, 2007.

CH IRO LEU, Adriana. La inclusión en la educación superior como política pública: tres experiencias en América Latina. Revista I beroamericana deEducación, v. 48, n. 5, M adrid, 0 EI, 2009. D isponibleen: «ttp://www.rieoei.org/deloslectores/2740C hiroleu.pdf $>$. Consultado el: 22/2/2009

DIAS SO BRIN H O , José; DE BRIT O, M arcia Regina. La Educación Superior en Brasil: principales tendencias y desafíos. Avaliação, v. 13, n. 2, 2008. Disponible en: বhttp:// www.scielo.br/scielo.php?pid=\$1414-772008000200011\& script=sci_arttext>. C onsultado em 21/09/2008

D O M IN GU ES, Petrônio. Ações afirmativaspara negrosno Brasil: o início deumareparação histórica. Espaço Aberto, n. 29, 2005. Disponibleen: বhttp://www.scielo.br/pdf/rbedu/n29/ n29a13.pdf>. Consultado el: 24/05/2008

FIT O U SSI, Jean Paul; RO SAN VALLO N , Pierre. La nueva era delas desigualdades. Buenos Aires: M anantial, 1997.

GO M ES, J oaquim Benedito Barbosa. As ações afirmativas e os processos de promoção da igualdade efetiva. In: SEM IN ÁRIO IN TERN ACIO N AL AS M IN O RIASE O DIREIT O, 2001, Braślia. Conselho daJ ustiça Federal, Centro deEstudos) udiciários; AJU FE; Fundação Pedro Jorge de M ello eSilva; TheBritsh Council. - Brasília. (SérieC adernos do CEJ , v. 24). D isponibleen 〈http://www.cjf.jus.br/revista/seriecadernos/vol24/artigo04/expediente. pdf>. Consultado el: 21/4/2008.

IBGE. Síntesis de indicadores sociales. D isponible en: «tttp:// www.ibge.gov.br/espanhol/ presidencia/noticias/noticia_impressao.php?id_noticia=987>. Consultado el: 22/09/2007.

M AN CEBO , D eise. Universidade para todos: a privatização em questão. Pro-Posições, v. 15, n. 3, p. 75 - 90, 2004. D isponibleen: «ttp:// www.an ped.org.br/reformauniversitaria4.doc>. Consultado el: 14/11/2007.

M AN IFEST 0 contra as cotas: todos têm direitos iguaisna República D emocrática (2006). D isponible en: বhttp://www1.folha.uol.com.br/folha/educacao/ult305u18773.shtml>. Consultado el: 15/02/2008.

M EC /IN EP. Sinopseda Educação Superior. Brasília, 2006. 
M EC . Reestruturação eE xpansão das U niversi dadesF ederais. Plano de D esenvolvimento da Educação. Braślia, 2007.

M O EH LECKE, Sabrina. Ação afirmativano Ensino Superior: entrea excelência eajustiça racial. Educação \& Sociedade, Campinas, v. 25, n. 88, p. 757-776, 2004. D isponible en: «tttp://www.scielo.br/scielo.php?script=sci_arttext\& pid=\$0101-73302004000300006 $\&$ Ing=en \& nrm=iso\& tlng=pt>. Consultado el: $22 / 11 / 2007$.

O RO ZCO SI LVA, LuísEnrique. Tareas pendientes delas universidades en América Latina. Q uorum - Revista de Pensamiento I beroamericano, U niversidad de Alcalá, M adrid, n. 15, 2006. Disponible en: «tttp://redalyc.uaemex.mx/redalyc/pdf/520/52001508. pdf>. Consultado el: 20/11/2007.

PAST O RE, José; D A SI LVA, N el son Valle N otassobrea mobilidadesocial noBrasil. SEM IN ARIO ESPECIAL M IN IFÓ RUM EM H OM EN AGEM AOS 40 AN OS DO IPEA, 2004, Rio de Janero. D isponibleen: www.inae.org.br/trf_arq.php?cod=EP00840. Consultado el:22/11/2007.

PEIXOTO , M aría do C armo. Políticas de admissão ao ensino superior no Brasil. Trajetória histórica epolíticas atuais. In: SEM IN ARIO TALLER IN TERN ACIO N AL PO LÍTICASY SISTEM AS DE ADMISIÓN Y NIVELACIÓN A LA UNIVERSIDAD EN AM ÉRICA LATIN A: DIAG N Ó ST ICOSY PERSPECTIVAS, 8 y 9 de diciembrede 2008, Q uito, 2008 RAW LS, John. Teoría dela justicia. BuenosAires: FCE, 1997.

REN AUT, Alain. La universidad frente a los desafíos de la democracia. In: SEM IN ARIO UN IVERSID AD Y DEM O CRACIA, 27 y 28 dejunio de2008, BuenosAires. 0 bservatorio de Educación Superior de la U niversidad N acional de San M artín, Buenos Aires, 2008. Disponible en: <http://www.unsam.edu.ar/insti/oespuR enaut\% 20\%20L a\%20 universidad \% 20frente $\% 20$ a $\% 201$ os $\% 2$ desaf $\%$ C 3\% AD os $\% 20$ de $\% 201$ la 20 democracia.pdf $>$. Consultado el: 18/8/2008.

RO CH A PIN TO, Paulo Gabriel H iluda; CLEM EN TE JU N IO R, Paulo Eugenio. Pensando a ação afirmativa: políticaspúblicas, relações raciaise práticasacadémicas, 2004. D isponibleen: «ttp://urutau.proderj.rj.gov.br/isp_imagens/U ploads/Artigo2005005.pdf $>$. Consultado el: 20/03/2008.

RO SAN VALLO N, Pierre. La nueva cuestión social: repensar el Estado providencia. Buenos Aires: M anantial, 1995.

SCH WART ZM AN , Simón. A nova reforma univers tária. São Paulo: Instituto deEstudos do Trabalho e Sociedade, 2004. Disponible en: «tttp://www.iets.org.br/notitia/servlet/ newstorm. notitia. presentation. $\mathrm{N}$ avigationServlet?publication $\mathrm{C}$ ode $=1 \&$ pageC ode $=$ $10 \&$ textC ode $=3488 \&$ date $=$ currentD ate $>$. Consultado el: $25 / 11 / 2007$.

SPU . Anuario deestadísticasuniverstarias. BuenosAires: Secretaría de Políticas U niversitarias, 2005.

SPU . Anuario deestadísticasuniverstarias. Buenos Aires: Secretaría de Políticas U niversitarias, 2006.

TEICH LER, U Irich. Lanaturaleza cambiantedela educación superior en laEuropa occidental. In:T EICH LER, U Irich (Ed.). Reformasdelosmodelosdela educación superior en Europa, Japón 
y América Latina: análisiscomparados. BuenosAires: Editora U niversidad deBuenosAires; M iño y D ávila, 2006. 379 p.

W ILLIAM SCREN SH AW, Kimberlé. En pos deuna defensa proactiva dela acción afirmativa: derribando mitos y reformulando el debate. In: DÍAZ RO M ERO, Pamela (Ed.). Caminos para la inclusión universitaria en Perú. OEI - Fundación Equitas, 2006. Disponible en: «ttp://www.fundacionequitas.org/publicacion.aspx?cod_idioma=ES\& id_publicacion=19>. Consultado el: 15/06/2008.

Recebido em 20 de outubro de2008 eaprovado em 18 demarço de2009. 